\title{
The effects of an artificially enhanced clinoptilolite in patients with irritable bowel syndrome
}

\author{
J C Lamprecht' ${ }^{\text {, S Ellis }}{ }^{2}$, J R Snyman ${ }^{3}$, I Laurens ${ }^{3 *}$ \\ ${ }^{1}$ Assistant Professor: Department of Clinical Pharmacy, King Khalid University, Abha, Saudi Arabia \\ ${ }^{2}$ Head: Statistical Consultation Services, North-West University, Potchefstoom Campus, South-Africa \\ ${ }^{3}$ Office of the Dean, Faculty of Health Sciences, University of Pretoria, Pretoria, South Africa \\ *Corresponding author, email: ilze@dermav.co.za
}

\begin{abstract}
Background: Irritable Bowel Syndrome (IBS) is one of the most common gastrointestinal disorders presenting in clinical practice. IBS is a functional bowel disorder in which abdominal pain or discomfort is associated with a change in bowel habit and with features of disordered defecation.
\end{abstract}

Methods: IBS candidates were enrolled in the study using the Rome III diagnostic criteria. Participants were identified as IBS-D (diarrhoea dominant), IBS-C (constipation dominant) as well as an IBS-M (mixed group). The participants were randomly assigned; for intention to treat with $750 \mathrm{mg}$ potentiated clinoptilolite three times daily or placebo. The primary endpoint was to determine whether or not the patient experienced adequate relief of symptoms.

Results: At the end of treatment $67 \%$ and $40 \%$ of patients were classified as overall responders in the potentiated clinoptilolite and placebo groups respectively $(\mathrm{N}=50)$. After week three of treatment the number of weekly responders was significantly higher $(p=0.048)$ in the potentiated clinoptilolite group compared to the Placebo group, and at week four of treatment the number of weekly responders was borderline significant higher in the potentiated clinoptilolite group $(P=0.06)$. Secondary endpoints were measured but the population size proved too small to realistically obtain statistical significance $(p>0.5)$.

Conclusion: Potentiated clinoptilolite shows clinical benefit, and should be tested further in larger clinical trials. In addition, potentiated clinoptilolite also shows reduced symptoms of IBD-D and IBS-M respectively. It is recommended that clinical response to dose variation should also be further investigated in designated populations of IBS-M and IBS-D patients.

Keywords: Irritable Bowel Syndrome; potentiated clinoptilolite; zeolite; randomised controlled trial; efficacy.

\section{Introduction}

Irritable Bowel Syndrome (IBS) is a common gastrointestinal (GI) disorder characterised by recurrent abdominal pain or discomfort, bloating and stool irregularities (constipation and/or diarrhoea). ${ }^{1}$ IBS tends to affect women more than men, ${ }^{2}$ probably due to sexual or biological differences. ${ }^{3}$ Almost a decade ago, Farthing contended that, "from the diverse collection of symptoms it seems unlikely that a single medication can reliably treat all aspects of the syndrome".4

IBS may be accompanied by other clinical manifestations, associated with the Gl-tract. Population based and large case studies have shown that one to two thirds of subjects with IBS have symptoms that overlap with functional dyspepsia. Other gut symptoms that were reported among IBS patients were heartburn, nausea, vomiting and early satiety. ${ }^{5}$

The objective of this trial was to explore the possibility of Absorbatox $^{\circledR}$, a potentiated clinoptilolite (mineral device) with unique adsorptive and absorption properties as treatment for IBS. A specific objective was measuring adequate relief as primary outcome.

Patients reporting adequate symptom relief from $50 \%$ of treatment weeks were regarded as responders to treatment. ${ }^{6-11}$ Secondary endpoints were assessed by means of the IBS Severity Scoring System. ${ }^{12,13}$ Stool frequencies, urgency and consistency were stool parameters.

The exact pharmacological action of Absorbatox ${ }^{\circledR}$ is not completely clear but the substance may play a role as an ameliorating agent in the ad- and absorption of certain endogenous chemicals which can cause Gl symptoms such as diarrhoea, bloating, distension and abdominal discomfort.

The rationale of the investigation was to establish the efficacy of Absorbatox ${ }^{\circledR}$, a zeolite with improved physiochemical properties and enhanced cat ion exchange capacity (CEC). This rendering a particle (device), which is more specific for binding intestinal molecules containing ad- or absorbable properties such as positively charged entities, like $\mathrm{NH}$-groups or free $\mathrm{NH}_{3}$, as a 
possible alternative treatment in IBS. Absorbatox ${ }^{\circledR}$ is essentially a sorptive, inert device which is not absorbed from the GIT but ad-and absorbs selective products in the GIT. The latter has been identified in in vitro assays specifically for Absorbatox ${ }^{\circledR}$, such as E. coli exotoxins, heavy metals, some allergens, fungal toxins (aflatoxin, zearalenone and ochratoxin) and biological autacoids (amines) such as histamine (data on file Absorbatox (Pty) Ltd).

\section{Absorbatox}

Absorbatox ${ }^{\circledR}$ is a patented name of an aluminosilicate belonging to the zeolite family (US Pat\#8758775 and 13177298 and 13943056). It is a potentiated clinoptilolite by means of exposing the natural zeolite to the physiochemical procedures, thereby improving the unique physiognomies. It has a significantly enhanced CEC of around 2-4 times higher than that found in nature.

Clinoptilolite is the most common natural zeolite found in sedimentary rock of volcanic origin. ${ }^{14}$ The clinoptilolite structure is a typical three-dimensional network of $\mathrm{AlO} 4$ and $\mathrm{SiO} 4$ arranged in a tetrahedral. ${ }^{15}$ This non-toxic zeolite has a monoclinic crystal symmetry, strong adsorptive and ion exchange capacity, and has been widely utilised by the industrial, agricultural and environmental industry. ${ }^{16}$ The zeolite has the ability to adsorb bile acids, ${ }^{17}$ harmful toxins, ${ }^{18}$ gasses including $\mathrm{CO}_{2}, \mathrm{CH}_{4}, \mathrm{H}_{2},{ }^{19} \mathrm{NH}_{3}{ }^{20}$ and it also has been shown to reduce bacterial contamination of the gut. ${ }^{21}$

It is established that some zeolites have antidiarrhoeal, ${ }^{22}$ immunostimulatory and antioxidative, ${ }^{23}$ antibacterial and antifungal, ${ }^{24}$ antacid $^{25}$ as well as glucose adsorbent-like properties. ${ }^{26}$

Animal and human data demonstrated the safety of clinoptilolite consumption. A laboratory animal study demonstrated that it was not associated with any toxic effects or biological damage. ${ }^{22}$ A safety report published in the International Journal of Toxicology did not mention any toxicity of particular concern with clinoptilolite. ${ }^{27}$

Powdered zeolites are inert and whenever ingested do not react chemically with food or body fluids or their metabolites. The risk of any associated adverse effects is therefore said to be insignificant. ${ }^{28}$

Zeolites and in particular Absorbatox ${ }^{\circledR}$ have been the topic of many safety studies both in vitro and in vivo demonstrating its safety. Extensive human exposure to clinoptilolites such as Absorbatox ${ }^{\circledR}$ is documented in various clinical conditions such as diarrhoea. Dosages of $5-31.1 \mathrm{~g} / \mathrm{kg}$ showed no accumulation or organ toxicity in test animals. Absorption is minimal and only $<1 \%$ of silicone is excreted in the urine of any dose and $99 \%$ was excreted in the faeces of rodents. ${ }^{29}$

The active product for this study consisted of $750 \mathrm{mg}$ Absorbatox ${ }^{\circledR}$ $\left[(\mathrm{Na}, \mathrm{Ca}, \mathrm{K})_{6} \mathrm{Si}_{30} \mathrm{Al}_{6} \mathrm{O}_{72} \cdot \mathrm{NH} 2 \mathrm{O}\right]$ per capsule.

\section{Methodology}

Clinical trials in IBS are difficult to design because, unlike other organic disease entities, IBS lacks a biological marker and its diagnosis is based on symptom criteria, therefore subjective scoring. ${ }^{30}$ The high placebo response seen in IBS patients enrolled in trials is also bothersome. Researchers are further challenged by selecting the most appropriate study duration and by being able to recruit appropriate patients. ${ }^{30,31}$

This study screened 94 patients for inclusion. After ethics committee approval (North West University ethics committee) and informed consent was signed. Recruited participants were assigned to the 2-week run-in phase of the study to assess baseline symptoms. Thereafter, participants were randomly assigned to either the active or placebo arms. This was a doubleblind, placebo-controlled study. Participants had to attend five study visits that were distributed over six weeks. It was expected of participants to complete a diary (booklet) throughout the trial period. This diary contained questionnaires that enabled the investigators to assess treatment effect. Participants were treated for four consecutive weeks after the initial run-in period (30 days).

A population sample size $(\mathrm{N}=54)$ was finally enrolled in the trial before randomisation. Of the initial 94 patients screened as possible candidates, 40 were disqualified as they either did not meet the Rome III criteria for inclusion or refused participation in a placebo controlled study. During the treatment phase another four participants were disqualified for reasons of: one being noncompliant; one contracted influenza; one's questionnaire was not completed during the baseline phase and one withdrew for personal reasons.

The final statistical analysis was performed on a sample size of 50 subjects, 25 subjects were on placebo and 25 on the active moiety.

\section{Outcome assessments}

Primary endpoints: Patients who report adequate relief from $50 \%$ of treatment weeks were regarded as responders. ${ }^{6-11}$

\section{Inclusion and Exclusion criteria}

IBS may be considered a valid diagnosis if the patient complains of abdominal pain and altered bowel habits in the absence of a structure or biochemical markers. Using extensive and expensive testing procedures is sometimes not valuable when patients, without alarm systems, fulfil the Rome III criteria. ${ }^{32}$ It is advisable to include as broad a spectrum of patients as possible, as commended by the Rome III criteria. ${ }^{27}$

Patients with alarm symptoms/conditions (weight loss, nocturnal predominant symptoms, progressive deterioration of symptoms, family history of colorectal cancer or inflammatory bowel disease) were excluded from recruitment. The main indications for exclusion as postulated by Corazziari were used: ${ }^{30}$

\footnotetext{
- Patients over 50 years of age who have not had a colonoscopy and patients of 50 years or younger who have not had a colonoscopy or sigmoidoscopy after the onset of IBS symptoms and within the previous 5 years;
}

- Patients with relevant abnormalities on physical examination; 
- Patients with an abnormal blood count or elevated sedimentation rate;

- Clinically evident disturbed behaviour and major psychiatric disorders;

- Female patients whose symptoms are suggestive of an underlying gynaecological disorder;

- Patients with suspected lactose intolerance, and;

- Patients with celiac disease.

Moreover, medication containing cations such as Lithium were also regarded as a criterion for exclusion in this particular study given the sorption nature of the test product.

\section{Participants}

Male and female participants over the age of 18 years were recruited in the North-West Province, South Africa, making use of recruitment from medical private practices and in pharmacies by means of flyers, and electronic invitations through mass mailing systems.

\section{Treatment}

Participants in the trial received $750 \mathrm{mg}$ Absorbatox ${ }^{\circ}$ or placebo capsules three times daily as oral soft gelatine capsules. This dosage was based on the founding of an unpublished study by Koot and associates in which 30 enterotoxin-induced NMRI mice were given different dosages of Absorbatox to assess efficacy (reduction in toxicity and stool frequency) ${ }^{33}$ as well as a study in patients with NGORD. ${ }^{34}$

The placebo capsules were similar in form, colour, taste, size and packaging to the potentiated clinoptilolite capsules.

\section{Statistical methods}

The StatSoft, Inc. (2013). STASTICA (data analysis software system), version 11. www.statsoft.com was used for analysis and the Chi-square test was used to determine associations between group membership and outcomes for each week.

\section{Demographics}

Two thirds (68\%) of the population presented with IBS-M (mixed IBS symptoms) and IBS-D (predominant diarrhoea symptoms) and only a third (32\%) presented with constipation as a predominant IBS-symptom (IBS-C). Interestingly, it was noticeable that more than half the participants (56\%) were overweight according to their BMI index.

Table 1 illustrates the demographic profiles before analysis. The method of randomisation ensured equal representation of characteristics among treatment groups. Although participants in the Absorbatox ${ }^{\circledR}$ group were on average older than participants in the Placebo group, no significant differences were observed in the duration of IBS symptoms (described as the number of years that patients are aware of bowel symptoms) and BMI index. In terms of bowel habit subtype (according to Rome III criteria), patients with mixed IBS (IBS-M) were almost equally represented throughout the treatment groups. Thirteen (13) IBS-M patients were allocated to the Placebo group, and sixteen (16) were allocated to the Absorbatox ${ }^{\circledR}$.
Table 1: Demographic characteristics before analysis

\begin{tabular}{|c|c|c|}
\hline & $\begin{array}{c}\text { Absorbatox }^{\circledR} \\
(\mathbf{n}=25)\end{array}$ & $\begin{array}{l}\text { Placebo } \\
(n=25)\end{array}$ \\
\hline Age (mean \pm SD) & $45.16 \pm 12.30$ & $34.48 \pm 14.38$ \\
\hline Male (n) & 3 & 3 \\
\hline Female (n) & 22 & 22 \\
\hline \multicolumn{3}{|l|}{ Race (n) } \\
\hline White & 24 & 25 \\
\hline Coloured & 1 & 0 \\
\hline Black & 0 & 0 \\
\hline $\mathrm{BMI}($ mean $\pm \mathrm{SD})$ & $26.84 \pm 5.89$ & $26.70 \pm 6.43$ \\
\hline Family history of IBS (\%) & 48 & 40 \\
\hline \multicolumn{3}{|l|}{ ROME III bowel classification (n) } \\
\hline IBS-C & 5 & 11 \\
\hline IBS-D & 4 & 1 \\
\hline IBS-M & 16 & 13 \\
\hline \multicolumn{3}{|l|}{ Symptoms (mean \pm SD) } \\
\hline $\begin{array}{l}\text { Duration of symptoms (years) }{ }^{\text {ns }} \\
\text { Medication usage (\%) } \\
\text { (previously used) }\end{array}$ & $12.31 \pm 10.47$ & $12.94 \pm 11.94$ \\
\hline Antacids/PPI users & 32 & 16 \\
\hline${ }^{*}$ CAM users & 52 & 40 \\
\hline * Tegaserod maleate users & 16 & 0 \\
\hline Laxative users & 28 & 32 \\
\hline Antidiarrhoeal users & 16 & 8 \\
\hline Antispasmodic users & 64 & 44 \\
\hline
\end{tabular}

ns - No statistically significant differences were noted between treatment groups $(P>0.05)$. CAM - Complementary and alternative medicine

* - International recall of Tegaserod - March 2007 (due to cardiac effects)

\section{Primary Outcomes (Adequate relief)}

Participants who qualified as overall responders were defined as the participants who indicated a positive response to treatment in $\geq 50 \%$ of the 4 treatment weeks.

At the end of the 28-day treatment (last 4 weeks), 40\% (10/25) of participants from the Placebo and $67 \%$ (16/24) of participants from the Absorbatox ${ }^{\circ}$ group were classified as overall responders. Table 2 is a summary of responders reported in both active and placebo arm.

A pronounced placebo effect was observed in the placebo arm that coincides with the findings in literature. However, the response to treatment in the active arm increased over time and reached significance in week three $(p=0.048)$ and borderline significance after four weeks of treatment $(p=0.06)$.

Over the four weeks of the trial, around $40 \%$ of those on the placebo arm experienced adequate relief in each of the four weeks. In the first week, approximately $32 \%$ of participants on the active treatment experienced adequate relief. This steadily increased to $67 \%$ in the final week on active treatment.

\section{Secondary endpoints}

It was not possible to obtain statistical significance in measuring secondary endpoints in this trial, as expected from the small number of participants in the trial. Some of the secondary endpoints measured were:

1) Bowel habit satisfactions;

2) Number of days with pain over the last 10 days and;

3) Interference with life (quality of life) 
Table 2: Overall responders

\begin{tabular}{|c|c|c|c|}
\hline \multicolumn{4}{|c|}{ Overall responders reported for Placebo and Active groups } \\
\hline Weekly intervals: & $\begin{array}{l}\text { Placebo arm } \\
\text { Responders (\%) }\end{array}$ & $\begin{array}{c}\text { Active arm } \\
\text { Responders (\%) }\end{array}$ & $\begin{array}{c}\text { *Pearson Chi-square } \\
\text { P-Values }\end{array}$ \\
\hline Week 1 & $\begin{array}{l}40.00 \\
n=25\end{array}$ & $\begin{array}{l}32.00 \\
n=25\end{array}$ & $P=0.56$ \\
\hline Week 2 & $\begin{array}{l}39.13 \\
\mathrm{n}=23\end{array}$ & $\begin{array}{l}52.00 \\
n=25\end{array}$ & $P=0.37$ \\
\hline Week 3 & $\begin{array}{l}36.00 \\
n=25\end{array}$ & $\begin{array}{l}64.00 \\
n=25\end{array}$ & $P=0.048$ \\
\hline Week 4 & $\begin{array}{l}40.00 \\
n=25\end{array}$ & $\begin{array}{l}66.67 \\
n=24\end{array}$ & $P=0.06$ \\
\hline
\end{tabular}

*Pearson $p$-values $<0.05$ is statistically significant

\section{Discussion}

This trial recruited patients from various resources using inclusion and exclusion criteria in concordance with literature recommendations. ${ }^{8,30,35}$ It must be mentioned that various IBS trials have ruled out organic cause by standard laboratory and radiological tests, and rectosigmoidoscopy. ${ }^{36-38}$ However, due to logistic reasons and with the intention to keep this trial as non-invasive as possible and naturalistic within the general practitioner environment, laboratory and radiological tests were not performed on IBS candidates unless clinically indicated and requested by the treating doctor.

At the end of treatment $67 \%$ and $40 \%$ of patients were classified as overall responders in the Absorbatox ${ }^{\circledR}$ and Placebo groups respectively $(\mathrm{N}=50)$ (see Figure 1$)$. After week three and week four of treatment, the number of weekly responders was significantly higher $(p<0.5)$ in the Absorbato ${ }^{\circledR}$ group compared to the Placebo group.

When patients with predominant constipation were excluded, IBS-C (constipation dominant group), then $74 \%$ of overall responders were found to be in the active group compared to $29 \%$ of overall responders in the placebo group $(p=0.01)$ (see Figure 2).

Absorbatox ${ }^{\circledR}$ treatment was more effective in the treatment of IBS-D (diarrhoea dominant) and IBS-M (mixed group) testing for adequate relief. Absorbatox ${ }^{\circledR}$ showed clinical benefit and warrants further exploration within the mentioned groups.

Although the placebo effect was largely present during the trial, the active treatment showed clinical benefit. The mechanism of action is not clear. However, as Absorbatox ${ }^{\circledR}$ has the ability to ad-

Figure 1: Percentage Patients Who Experienced Adequate Relief

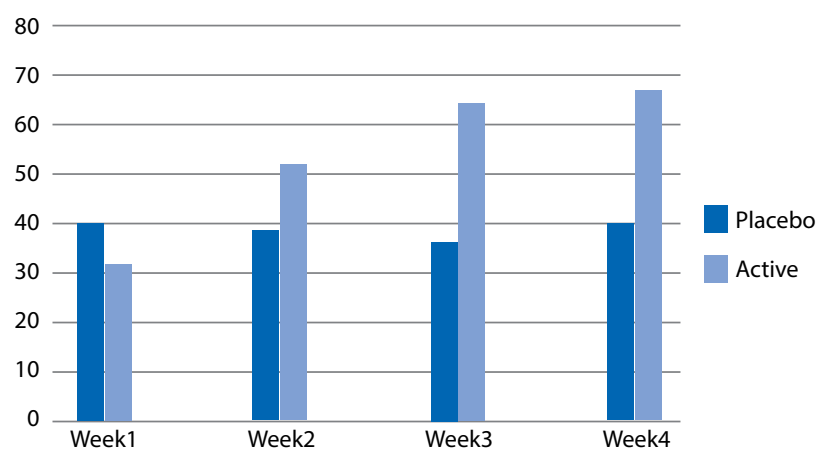

$\mathrm{N}=50(\mathrm{p}<0.05)$
Figure 2: Percentage Patients Who Experienced Adequate Relief (IBS-C excluded)

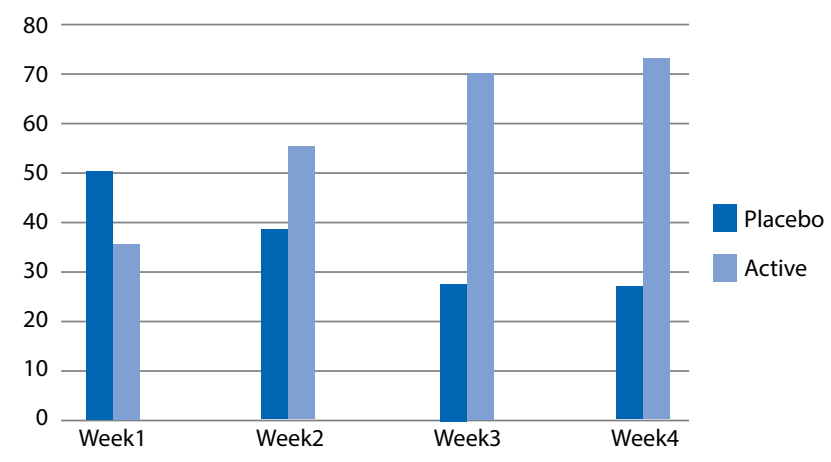

* IBS-C data excluded; $\mathrm{N}=34(\mathrm{p}=0.01)$

or absorb bile acids, harmful toxins, gasses $\left(\mathrm{CO}_{2}, \mathrm{CH}_{4}, \mathrm{NH}_{3}\right)$ and bacterial toxins in vitro may partially explain its efficacy in IBS. This warrants further exploration in larger clinical trials.

\section{Ethical considerations}

Guidelines set out by the ICH Good Clinical Practice Guidelines and the World Medical Association Declaration of Helsinki (2004) were followed in the preparation of the study protocol. The protocol was authorised by the Ethics Committee of the North-West University, Potchefstroom, South Africa (Ethical approval no. nwu-0001-08-S5). The trial was also registered with the South African Clinical Trial Register (SANCTR) online at www.sanctr.gov.za, the application ID no. 1631. All participants gave written informed consent for participation.

\section{Acknowledgements}

- Jesslee du Plessis, medical physician, who consulted the patients medically.

- JR Kloppers primary researcher for concluding an interim analysis of the trial for the purposes of a dissertation submitted in partial fulfilment of the requirements for the degree Magister Pharmaciae. ${ }^{22}$

- Co-supervisors, Mr GK John and Prof JR Snyman, the mentioned dissertation submitted at the NWU, with special thanks to Mr George John for partnering with the National Research Foundation and allowing the primary researcher to NRF funding.

- Sponsors of the active and placebo substances manufactured by Brunel Farmaseutika (Pty) Ltd. available in South Africa from Absorbatox (Pty) Ltd. as a non-scheduled substance and 
is pharmacologically classified as an A32.2 substance (referred to as "Other") (Absorbatox, 2008).

- Other Sponsoring companies: Aspen Pharmacare, CiplaMedpro, Mylan (previously Merck-Generics) sponsoring rescue medication.

\section{Competing Interests}

This trial was conducted at the North-West University, Potchefstroom campus, South Africa. An interim analysis in the format of a dissertation was submitted by JR Kloppers as partial fulfilment of the requirements for the degree Magister Pharmaciae in Clinical Pharmacy at the Potchefstroom campus of the North-West University in South Africa. The sponsors are listed and acknowledged.

\section{Contributions acknowledged}

JC Lamprecht - Author, researcher and study leader for JR Kloppers.

RJ Kloppers - Primary researcher doing a pilot study in the Department of Clinical Pharmacy, School of Pharmacy at the North-West University, Potchefstroom Campus.

\section{JR Snyman - Co-supervisor for JR Kloppers.}

G John - Co-supervisor for JR Kloppers.

S Ellis - Co-editor and statistician at Statistical Consultant Services, Potchefstroom Campus, North-West University.

\section{Form of Grants}

\section{National Research Foundation (NRF): Mr George John facilitated} the primary research to NRF funding.

Sponsors: Active ingredient, placebo and rescue medication is acknowledged under the heading "Acknowledgements".

\section{References}

1. Longstreth GF, Thompson WG, Houghton LA, Mearin F, Spiller RC. Functional bowel disorders. Gastroenterology. 2006;130(5):1480-91.

2. Payne S. Sex, gender and irritable bowel syndrome: making the connections. Gend Med. 2004;1(1):18-28.

3. Rahimi R, Nikfar S, Abdollahi M. Efficacy and tolerability of alosetron for the treatment of irritable bowel syndrome in women and men: a meta-analysis of eight randomized, placebo-controlled, 12 Week trials. Clin Ther. 2008;30(5):884-901.

4. Farthing MJ. Irritable bowel syndrome: new pharmaceutical approaches to treatment. Baillieres Best Pract Res Clin Gastroenterol. 1999;13(3):461-71.

5. Cremonini F, Talley NJ. Review article: the overlap between functional dyspepsia and irritable bowel syndrome: A tale of one or two disorders. Aliment Pharmacol Ther. 2004;20:40-9.

6. Camilleri M, Mangel AW, Fehnel SE, Drossman DA, Mayer EA, Talley NJ. Primary endpoints for irritable bowel syndrome trials: a review of performance of endpoints. Clin Gastroenterol Hepatol. 2007;5(5):534-40.

7. Camilleri M, Northcutt AR, Kong S, Dukes G, McSorley D, Mangel AW. Efficacy and safety of alosetron in women with irritable bowel syndrome: a randomised, placebo-controlled trial. Lancet. 2000;355(9209):1035-40.

8. Design of Treatment trails committee, Irvine EJ, Whitehead WE, Chey WD, Matsueda K, Shaw M, et al. Design of treatment trials for functional gastrointestinal disorders. Gastroenterology. 2006;130:1538-51.

9. Jones R. Likely impacts of recruitment site and methodology on characteristics of enrolled patient population: irritable bowel syndrome clinical trial design. Am J Med. 1999;107(5A):85S-90S.

10. Kim HJ, Vazquez Roque MI, Camilleri M, Stephens D, Burton DD, Baxter K, et al. A randomised controlled trial of a probiotic combination VSL\# 3 and placebo in irritable bowel syndrome with bloating. Neurogastroenterol Motil. 2005;17:687-96.

11. Schoenfeld P, Talley NJ. Measuring successful treatment of irritable bowel syndrome: is satisfactory relief enough? Am J Gastroenterol. 2006;101(15):1066-68.
12. Francis CY, Morris J, Whorwell PJ. The irritable bowel syndrome severity scoring system: a simple method of monitoring irritable bowel syndrome and its progress. Aliment Pharmacol Ther. 1997;11(2):395-402.

13. Bijkerk CJ, De Wit NJ, Muris JWM, Jones RH, Knottnerus JA, Hoes AW. Outcome Measures in Irritable Bowel Syndrome: Comparison of Psychometric and Methodological Characteristics. Am J Gastroenterol. 2003;98(1):122-27.

14. Zarkovic N, Zarkovic K, Kralj M, Borovic S, Sabolovic S, Blazi MP, et al. Anticancer and antioxidative effects of micronised zeolite clinoptilolite. Anticancer Res. 2003;23:1589-95.

15. ABSORBATOX. http://www.absorbatox.com/bowel-balance.html (Accessed 10 September 2008).

16. Grce M, Pavelic K. Antiviral properties of clinoptilolite. Microporous and Mesoporous Mater. 2005;79:165-9.

17. Carballo S, Rodriguez-Fuentes $G$, Urbina C, Fleitas A. Study of the reaction of a Ca-clinoptilolite and human bile. Stud Surf Sci Catal. 2001;135:170.

18. Ward TL, Watkins KL, Southern LL. Interactive effects of sodium zeolite A and Eimera acervulina infection on growth and tissue minerals in chicks. Poult Sci. 1993;72:2172-5.

19. Ackley MW, Rege SU, Saxena H. Application of natural zeolites in the purification and separation of gases. Microporous and Mesoporous Mater. 2003;61:25-42.

20. Mumpton FA. La roca magica: uses of natural zeolites in agriculture and industry. Proc Natl Acad Sci USA. 1999;96(7):3463-6470.

21. Varel VH, Robinson IM, Pond WG. Effect of dietary copper sulfate, Aureo SP250, or clinoptilolite on ureolytic bacteria found in the pig large intestine. App Environ Microbiol. 1987;53(9):2009-12.

22. Rodirguez-Feuntes G, Barrios MA, Iraizoz A, Perdomo I, Cedre B. Enterex: anti-diarrheic drug based on purified natural clinoptilolite. Zeolites. 1997;19:441-8.

23. Pavelic K, Katic M, Sverko V, Marotti T, Bosnjak B, Stojkovic R. Immunostimulatory effect of natural clinoptilolite as a possible mechanism of its antimetastatic ability. J Cancer Res Clin Oncol. 2002;128(1):37-44.

24. Maeda T, Nose Y. A new antibacterial agent: antibacterial zeolite. Artif Organs. 1999;23(2):129-30.

25. Rodriguez-Fuentes G, Denis AR, Barrios MA, Colarte Al. Antacid drug based on purified natural clinoptilolite. Microporous and Mesoporous Mater. 2006;94:200-7.

26. Concepcion-Rosabal G, Rodriguez-Fuentes G, Simon-Carballo R. Development and featuring of the zeolitic active principle FZ: A glucose adsorbent. Zeolites. 1997;19:47-50.

27. Elmore AR. Final report on the safety assessment of aluminum silicate, calcium silicate, magnesium aluminum silicate, magnesium silicate, magnesium trisilicate, sodium magnesium silicate, zirconium silicate, attapulgite, bentonite, Fuller's Earth, hectorite, kaolin, lithium magnesium silicate, lithium magnesium sodium silicate, montmorillonite, pyrophyllite, and zeolite. Int J Toxicol. 2003;22Suppl1: 37-102.

28. Ivkovic S, Deutch U, Silberbach A, Walraph E, Mannel M. Dietary supplementation with the tribomechanically activated zeolite clinoptilolite in immunodeficiency: effects on the immune system. Adv Ther. 2004;21(2):135-47.

29. Snyman JR. Executive summary on safety of Absorbatox ${ }^{\circledR}$ for use in humans. School of Medicine. Faculty of Health Sciences. University of Pretoria. South Africa. 2006 (Unpublished).

30. Corazziari E, Bytzer P, Delvaux G, Holtmann G, Malagelada JR, Morris J, et al. Consensus report: clinical trial guidelines for pharmacological treatment of irritable bowel syndrome. Aliment Pharmacol Ther. 2003;18(6):569-80.

31. Spiller RC. Problems and challenges in the design of irritable Bowel Syndrome Clinical Trials: Experience from Published Trials. Am J Med. 1999:107(5A):91S-97S.

32. Holten KB. Irritable bowel syndrome: minimize testing, let symptoms guide treatment. J Fam Pract. 52(12):942-50.

33. Koot D, Snyman JR, Brown D. An in vivo investigation of Absorbatox as an ameliorating agent in enterotoxin-induced diarrhoea. School of Medicine. Faculty of Health Sciences. University of Pretoria. South Africa. 2006 (Unpublished).

34. Potgieter W, Samuels CS, Snyman JR. Potentiated clinoptilolite: artificially enhanced aluminosilicate reduces symptoms associated with endoscopically negative gastroesophageal reflux disease and nonsteroidal anti-inflammatory drug induced gastritis. Clin Exp Gastroenterol. 2014;7:215-20.

35. Bergmann JF. Inclusion and exclusion criteria of importance in irritable bowe syndrome trials. Am J Med. 1999;107(5A):59-64.

36. Johanson JF,Drossman DA, Panas R, Wahle A, Ueno R. Clinical trial: phase 2 study of lubiprostone for irritable bowel syndrome with constipation. Aliment Pharmacol Ther. 2008;27(8):685-96.

37. Vahedi H, Merat S, Momtahen S, Kazzazi AS, Ghaffari N, Olfati G, Malekzadeh R. Clinical trial: the effect of amitriptyline in patients with diarrhoea-predominant irritable bowel syndrome. Aliment Pharmacol Ther. 2008;27:678-84.

38. Vejdani R, Shalmani HRM, Mir-Fattahi M, Sajed-Nia F, Abdollabi M, Zali MR, et al. The efficacy of an herbal medicine, Carmint, on the relief of abdominal pain and bloating in patients with irritable bowel syndrome: a pilot study. Dig Dis Sci. 2006:51(8):1501-07. 